\title{
31. Use of a New Diamond Composite for Multianvil High-pressure Apparatus
}

\author{
By Tetsuo IrIfune, ${ }^{*)}$ Wataru Utsumi, ${ }^{* *)}$ and Takehiko YagI**) \\ (Communicated by Syun-iti AкImoтo, M. J. A., Dec. 14, 1992)
}

\begin{abstract}
A newly developed diamond composite (Advanced Diamond Composite, $\mathrm{ADC}$ ) was tested as the anvil material for a double-stage multianvil (MA6-8) apparatus. Pressures over $30 \mathrm{GPa}$ at room temperature were produced at relatively small press loads without any significant damages on the ADC anvils. The ADC anvil was found to be more transparent to X-ray beams of a wide range of energy as compared with a competitive sintered polycrystalline diamond (SYNDIE), and is accordingly suitable for an X-ray window under pressure. Electrical resistivity of ADC, however, is higher by about one order of magnitude than that of SYNDIE, which would restrict its use as a lead for electric power supply to the furnace. A hybrid anvil system with four ADC anvils plus four tungsten carbide anvils, the latter being used as the electric leads, was introduced for high temperature runs. This system has enabled to generate temperatures to $1500^{\circ} \mathrm{C}$ at pressures of 25-33 GPa and to synthesize high-pressure phases relevant to the lower mantle mineralogy.
\end{abstract}

Key words: High-pressure generation; multianvil apparatus; advanced diamond composite; sintered polycrystalline diamond; mineral physics.

Introduction. Recent progress of the technology with multianvil 6-8 (MA6-8) apparatus permits generation of pressures exceeding $25 \mathrm{GPa}$. However, the maximum pressure available in this type of apparatus is usually limited to $27-28 \mathrm{GPa}$, because of the plastic deformation of tungsten carbide (WC) anvils under these conditions. Use of harder material is thus essential to reach higher pressures. Sintered polycrystalline diamond (PCD) composite is the one suitable for such anvil material. Some attempts have been made to use PCD as the anvils for various types of high pressure apparatus, including the second stage anvils of MA6-8 apparatus, ${ }^{1)-3)}$ double-stage opposed anvils (MA6-2), ${ }^{4)}$ Bridgman-type opposed anvil, ${ }^{5)}$ and those for a Drickamer-type cell. ${ }^{6), 7)}$

Several companies currently provide PCDs, but the sizes of most of these products are normally so small that they are generally unsuitable for the anvils for high-pressure apparatus. Amongst them, almost the unique product that meets this purpose is SYNDIE, which is supplied by the De Beers Co. Ltd. However, the anvils made of this material are quite expensive, because the processes for sintering diamond grits require high pressures of over $5.5 \mathrm{GPa}$ (diamond stability field) and also because rather complicated processes of cutting and polishing are needed to manufacture the anvils. Recently, Ringwood et al. ${ }^{8)}$ developed a process for fabricating a new diamond composite (Advanced Diamond Composite, $\mathrm{ADC}$ ), and the products are now available on a commerical basis. We have tested the performance of this material as the second stage anvils for a MA6-8 apparatus.

Advanced diamond composite. Ringwood $e t a l .{ }^{8)}$ reported that ADC is produced from natural diamond grits at pressures of about $2.0-2.5 \mathrm{GPa}$ and a temperature near $1500^{\circ} \mathrm{C}$.

*) Department of Earth Sciences, Ehime University, Matsuyama 790, Japan.

**) Institute for Solid State Physics, University of Tokyo, Roppongi, Tokyo 106, Japan. 
This lower pressure process has the advantage of cost savings as compared with other competitive PCDs. Moreover, the ADC process is capable of making much larger products than have been produced by other processes. It is now possible to make cylinders with about $25 \mathrm{~mm}$ diameter and the similar length (A.E. Ringwood, personal communication, 1992).

ADC is produced by the reaction of molten silicon with diamond. The silicon reacts to form cubic silicon carbide, which then forms a strong bond between the diamond particles. ADC also has a substantial electrical conductivity and can be shaped by an electrical discharge machine. Ringwood et al. ${ }^{8)}$ claim that ADC is several times as hard as the $\mathrm{K} 10$ class tungsten carbides and also has similar toughness to these tungsten carbides. It is also suggested that $\mathrm{ADC}$ is thermally stable and can be used up to about $1200^{\circ} \mathrm{C}$ without significant loss of its hardness.

Experimental method. We have used ADC cubes of $9.5 \mathrm{~mm}$ edge lengths, which were made by the electrical discharge processing without subsequent polishing. The all corners of the cubes were truncated by edge lengths of either 1.0 or $1.5 \mathrm{~mm}$ (TEL $=1.0$ and 1.5 $\mathrm{mm}$ ). In the present study, all of the runs were made using a cell assembly for TEL $=1.0$ $\mathrm{mm}$.

Some of the properties of the ADC anvils were measured and compared with those of the anvils made of SYNDIE: Electrical resistivities of these cubes, sandwiched by copper contacts, were measured as a function of the applied uniaxial press load. Moreover, the $\mathrm{X}$-ray transmissivities for these anvils were measured using a synchrotron radiation beam at the Photon Factory, National Laboratory for High Energy Physics (KEK). A white $\mathrm{X}$-ray beam was irradiated on a cylindrical sample made of a mixture of powdered $\mathrm{NaCl}$ and $\mathrm{Au}$, with a diameter of $1 \mathrm{~mm}$ and about $1 \mathrm{~mm}$ long, and the diffracted X-ray was detected by an energy dispersive method using a solid-state detector. The intensities $\left(\mathrm{I}_{0}\right)$ for the diffraction peaks were measured in an energy interval between 30 and $80 \mathrm{keV}$. The $\mathrm{ADC}$ or SYNDIE anvils of $9.5 \mathrm{~mm}$ thick were then placed just before the sample, and the intensities (I) for the corresponding diffraction peaks were measured in the similar manner. The X-ray transmissivity is defined here by the $\mathrm{I} / \mathrm{I}_{0}$ ratio for the anvil with a thickness of $9.5 \mathrm{~mm}$.

The assembled eight anvils (MA8) were pressurized in a newly installed cubic press (CAPRICORN-1) in ISSP, University of Tokyo. The first stage six anvils (MA6) are made of tungsten carbide with squared anvil heads of $18 \mathrm{~mm}$ edge lengths, to which uniaxial press loads up to 500 tons can be applied. The alignments of these first stage anvils were carefully adjusted before the experimental run.

The performance of the ADC anvils in high pressure generation was evaluated by measuring the press load needed to observe the covalent-metallic transition in $\mathrm{GaP}(\sim 23$ GPa). For comparison, the following sets of the MA8 anvils were used; (A) all ADC anvils, (B) four $\mathrm{ADC}$ plus four WC anvils, and (C) all WC anvils. The tungsten carbide used here is the hardest one (Sumitomo F0) tested by Irifune et al. ${ }^{9)}$ The damages of the anvils were carefully examined after each run.

Several high temperature runs under pressure have been made using the MA8 assemblage (B), the four WC anvils being used as the contacts for the electrical power supply to the furnace (Fig. 1(a)). The cell assemblage used in the present study is similar to that described in Irifune et al., ${ }^{9)}$ as shown in Fig. 1(b). The starting material was enclosed in the platinum capsule with an inner diameter of $0.4 \mathrm{~mm}$ and about $0.6 \mathrm{~mm}$ long, and the temperature just adjacent to the capsule was measured using a W97\%Re3\%-W75\%Re25\% thermocouple. The temperature thus measured may suffer uncertainties of about $10 \%$ of the nominal value as the hot junction of the thermocouple is not directly in contact with the sample. The recovered product was examined by X-ray powder diffraction method using a 


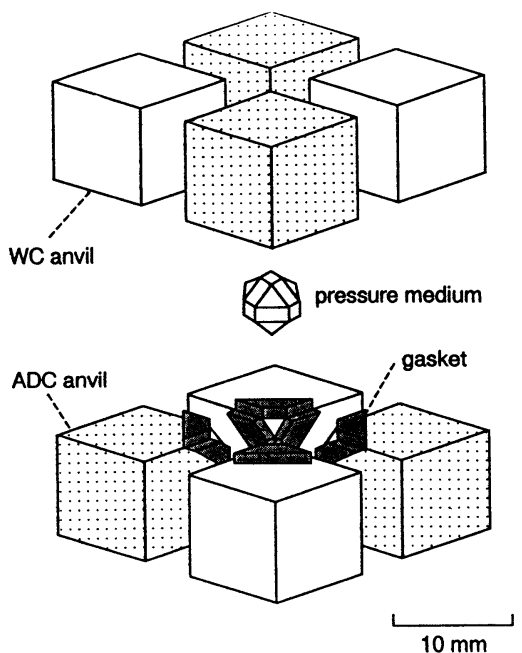

(a)

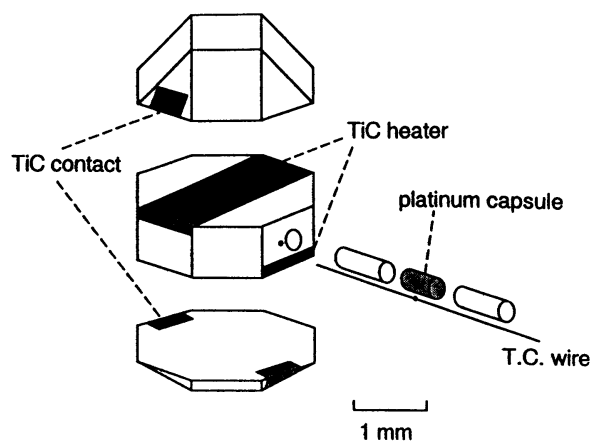

(b)

Fig. 1. Schematic illustrations of the hybrid anvil system adopted in the present high temperature runs for MA8 apparatus (a), and the furnace assembly used in these runs (b). The pressure medium is made of semi-sintered magnesia.

$57.3 \mathrm{~mm}$ Debye camera and, in some cases, with an analytical electron microscope.

Electrical resistivity and X-ray transmissivity. The electrical resistance of the ADC anvil decreased rapidly with increasing press load because of the large contact resistance at low pressure, and it approached to a constant value at a press load of 5.5 tons $(\sim 0.6$ $\mathrm{GPa})$. The obtained electrical resistivity of ADC at this pressure was about $0.05 \Omega \cdot \mathrm{cm}$, which is one order of magnitude higher than that measured here for SYNDIE $(\sim 0.004 \Omega \cdot \mathrm{cm})$ at the same pressure. The electrical resistance of the present ADC anvil $(\sim 40 \mathrm{~m} \Omega)$ is thus in the similar range as are those of typical heating elements $(10-100 \mathrm{~m} \Omega)$, and accordingly this anvil seems unsuitable for the lead for electric power supply.

The X-ray transmissivities of the ADC and SYNDIE anvils are compared in Fig. 2 as a function of energy. The ADC anvil was found to have apparently higher transmissivity than that of SYNDIE for all energies studied here. The transmissivity tends to decrease with decreasing energy in the present range, and only less than a few $\%$ of the initial

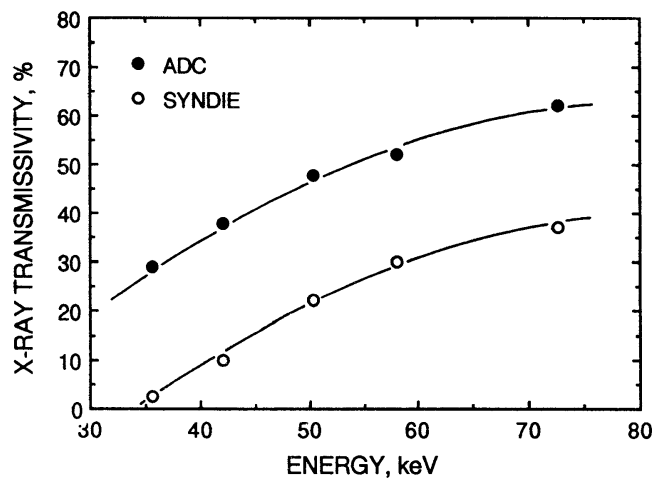

Fig. 2. X-ray transmissivities of the ADC and SYNDIE anvils of $9.5 \mathrm{~mm}$ thick as a function of the X-ray energy. 
intensity is available using the SYNDIE anvil at the energies lower than $40 \mathrm{keV}$, whilst the transmissivity of the ADC anvil remains about $30 \%$ even in this energy range.

High-pressure generation. The covalent-metallic transition in $\mathrm{GaP}$ was detected at a press load of about 145 tons using the system (A) comprising of eight ADC anvils, whilst it was observed at 205 tons in the (C) assemblage (all WC anvils) and at 170 tons in (B) (half ADC and half WC anvils). The use of the ADC anvils thus indeed improved the efficiency of the pressure generation as shown in Fig. 3, suggesting that pressures over $40 \mathrm{GPa}$ may be produced using the (A) system within the capacity of the present first stage anvils in CAPRICORN-1. Even if we adopt the (B) system, pressures well beyond $30 \mathrm{GPa}$ would be obtained at the press loads greater than about 300 tons. It should be noticed, however, that the pressures above $25 \mathrm{GPa}$ are extrapolated rather arbitrarily. Nevertheless, the absence of plastic deformations in the ADC anvils and the pressure calibration curves reported in an earlier work $^{2)}$ based on in-situ X-ray measurements using PDC anvils suggest that the present extrapolation is quite reasonable.

Six runs have been performed at pressures over $25 \mathrm{GPa}$ and at room temperature. No significant damages of the ADC anvil have been recognized, whilst the tungsten carbide anvils were found plastically depressed by about up to $40 \mu \mathrm{m}$ around the pressurized corners. No "blowout" has been experienced in the course of the high-pressure run including the unloading process, and both $\mathrm{ADC}$ and $\mathrm{WC}$ anvils could be repeatedly used in the subsequent runs.

Synthesis of high-pressure phases. In order to demonstrate the applicability of the present diamond composite to high-pressure mineral physics, nearly 10 runs have so far been made using the hybrid anvil system (B) at temperatures of 1000 and $1500^{\circ} \mathrm{C}$ and at 25-33 GPa as listed in Table I. Run durations were limited to typically several minutes to avoid the damages on the anvils and, in some cases, because of the malfunction of the heating system. $\mathrm{MgSiO}_{3}$ and $(\mathrm{Mg}, \mathrm{Fe})_{2} \mathrm{SiO}_{4}$ compositions were found to completely transform into the perovskite structure (plus magnesiowüstite, in the latter composition), in agreement with the phase diagrams established by Ito and Yamada ${ }^{10)}$ and Ito and

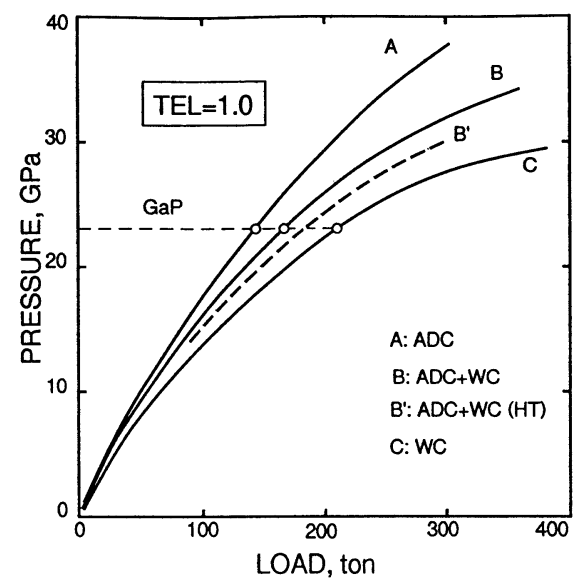

Fig. 3. Pressure calibration curves obtained on the basis of the covalentmetallic transition in $\mathrm{GaP}$ for the MA8 systems using the second stage anvils of all $\mathrm{ADC}(\mathrm{A}), 4 \mathrm{ADC}+4 \mathrm{WC}(\mathrm{B})$, and all $\mathrm{WC}(\mathrm{C})$. These curves were extrapolated in accordance with the earlier works with PCD anvils ${ }^{2)}$ and $\mathrm{WC}$ anvils. ${ }^{9)} \mathrm{B}^{\prime}$ is the calibration curve at high temperature $\left(\sim 1500^{\circ} \mathrm{C}\right)$ based on a run for the $\mathrm{MgSiO}_{3} \cdot 10 \% \mathrm{Al}_{2} \mathrm{O}_{3}$ composition. 
Table I. Experimental conditions and results for high temperature runs using the present hybrid anvil system

\begin{tabular}{llcccccc}
\hline Run No. & \multicolumn{1}{c}{ Sample } & $\begin{array}{c}\text { Press. } \\
(\mathrm{GPa})\end{array}$ & $\begin{array}{c}\text { Temp. } \\
\left({ }^{\circ} \mathrm{C}\right)\end{array}$ & $\begin{array}{c}\text { Time } \\
(\mathrm{min} .)\end{array}$ & Results & $\begin{array}{c}\text { Anvil damages* } \\
\text { (ADC) }(\mathrm{WC})\end{array}$ \\
\hline $\mathrm{C}-7$ & $\mathrm{MgSiO}_{3}$ & 27 & 1500 & 2 & $\mathrm{Pv}$ & 0 & 0 \\
$\mathrm{C}-8$ & $\mathrm{MgSiO}_{3} \cdot 10 \% \mathrm{Al}_{2} \mathrm{O}_{3}$ & 24 & 1500 & 5 & $\mathrm{Ilm}+\mathrm{Ga}$ & 1 & 1 \\
$\mathrm{C}-9$ & $\left(\mathrm{Mg}_{0.9} \mathrm{Fe}_{0.1}\right)_{2} \mathrm{SiO}_{4}$ & 29 & 1500 & 3 & $\mathrm{Pv}+\mathrm{Mw}$ & 0 & 0 \\
$\mathrm{C}-10$ & $\left(\mathrm{Mg}_{0.9} \mathrm{Fe}_{0.1}\right)_{2} \mathrm{SiO}_{4}$ & 33 & 1500 & 1 & b.o. & 1 & 3 \\
$\mathrm{C}-11$ & $\mathrm{MgSiO}_{3} \cdot 10 \% \mathrm{Al}_{2} \mathrm{O}_{3}$ & 26 & 1000 & 15 & u.d. & 0 & 0 \\
$\mathrm{C}-12$ & $\mathrm{Mg}_{3} \mathrm{Al}_{2} \mathrm{Si}_{3} \mathrm{O}_{12}$ & 29 & 1000 & 5 & $\mathrm{Ga}$ & 0 & 0 \\
$\mathrm{C}-13$ & $\mathrm{pyrolite}_{\mathrm{C}-14}$ & 29 & 1500 & 2 & $\mathrm{Pv}+\mathrm{Mw}+\mathrm{CaPv}$ & 3 & 1 \\
& $\left(\mathrm{Mg}_{0.9} \mathrm{Fe}_{0.1}\right)_{2} \mathrm{SiO}_{4}$ & 29 & 1500 & 10 & $\mathrm{Pv}+\mathrm{Mw}$ & 1 & 1 \\
\hline
\end{tabular}

* The same anvil set was repeatedly used after 6 runs at $25-35 \mathrm{GPa}$ at room temperature. "Damage" means here the presence of cracks visually recognized on the anvil surfaces. The damaged anvil was replaced by a new one in the subsequent run. b.o., blowout during heating; u.d., under determination.

$\mathrm{Pv}=\mathrm{MgSiO}_{3}$-perovskite; $\mathrm{Ilm}=\mathrm{MgSiO}_{3}$ ilmenite; $\mathrm{Ga}=$ garnet; $\mathrm{Mw}=$ magnesiowüstite; $\mathrm{CaPv}=\mathrm{CaSiO}_{3}$ perovskite.

Takahashi. ${ }^{11)}$ The results for other compositions were also consistent with those expected from earlier works. ${ }^{12), 13)}$

The pressures under high temperature were estimated using the $\mathrm{MgSiO}_{3} \cdot 10 \% \mathrm{Al}_{2} \mathrm{O}_{3}$ composition according to the method proposed by Irifune et $a l{ }^{13)}$ on the basis of the phase diagram of the $\mathrm{MgSiO}_{3}-\mathrm{Mg}_{3} \mathrm{Al}_{2} \mathrm{Si}_{3} \mathrm{O}_{12}$ system. These pressures appear to slightly ( $\left.\sim 5 \%\right)$ drop from those based on the room-temperature calibration, as shown in Fig. 3. No plastic deformations of the ADC anvils have been observed after these high temperature runs. A few ADC anvils, however, have cracked or chipped after one blowout during heating at 33 GPa and some runs at $1500^{\circ} \mathrm{C}$, as shown in Table I.

Discussion. It has been demonstrated that the ADC anvil is highly transparent to X-ray beams as compared with that of SYNDIE, and accordingly is suitable for an X-ray window under compression. This is due to the presence of appreciable amount of cobalt in the latter material as a binder, whilst $\mathrm{ADC}$ contains $\mathrm{SiC}$ which possesses a lower average atomic number. This compositional difference in turn leads to relatively higher electrical resistivity in $\mathrm{ADC}$. The use of the $\mathrm{ADC}$ anvils as the electric leads thus would be very limited.

In the present high temperature experiments, a hybrid anvil system in which four ADC anvils were replaced by WC anvils, was introduced to avoid such a problem. The maximum pressure available in this system is apparently higher than that obtained in conventional systems using WC anvils, and stable generation of high temperatures to $1500^{\circ} \mathrm{C}$ is possible without significant modifications of the cell assembly developed for the multianvil apparatus. Moreover, only one blowout has been experienced over 10 runs using the present hybrid system. This is of very good performance as compared with the experiments using PCD for all anvils, in which the blowout occurs more frequently ( $T$. Kondo, personal communication 1992).

The PCDs, including ADC, are generally several times as hard as tungsten carbide, and essentially no plastic deformation is observed in PCD anvils after high-pressure runs. On the other hand, WC anvils tend to significantly deform at pressures beyond about 20 $\mathrm{GPa}$, which is primarily responsible for the ineffective generation of pressure against the applied press load under such a pressure regime (e.g., Irifune et al. ${ }^{9)}$ ). We suppose, however, this deformation should contribute somehow to confine the pressure, as the 
depression of the anvil near the truncated edge tends to increase the inward component (i.e. the component toward the pressure medium) of the applied force to the gasket via anvils. The present hybrid system, in which each preformed pyrophyllite gasket is sandwiched by an ADC anvil and a WC anvil, utilizes this mechanism to prevent blowout. It appears likely that this actually works under the pressure and temperature conditions studied here.

After more than 10 runs, including 8 high temperature runs, at about $30 \mathrm{GPa}$, a few $\mathrm{ADC}$ anvils have been cracked. Most of such damages occurred in the runs at a temperature of $1500^{\circ} \mathrm{C}$ as shown in Table I. It is premature to conclude that this is caused by the weakening of $\mathrm{ADC}$ at high temperature, as we have not obtained enough data at the present stage. Further modifications of the furnace design could suppress such damages to occur at high temperature. Moreover, it appears necessary to modify the entire furnace/gasket system to get higher pressures utilizing the potential of the ADC anvils. Use of other gasket materials including metal (e.g., Yoneda et al. ${ }^{14)}$ ) should be seriously considered to achieve this purpose.

Acknowledgments. The authors thank Prof. A. E. Ringwood for the benefit of discussion and help to use ADC for multianvil apparatus. They also thank Prof. S. Akimoto, M. J. A., for encouragements and comments during the present work. This work is supported by Grant-in-Aid for Scientific Research from the Ministry of Education, Science and Culture of the Japanese Government.

\section{References}

1) Endo, S. et al. (1987): Jpn. J. Appl. Phys., 26, L1419-1420.

2) Ohtani, E. et al. (1989): Rev. Sci. Instrum., 60, 922-925.

3) Kondo, T. et al. (1991): Abst. 32nd High Press. Conf. Japan, pp. 54-55 (in Japanese).

4) Utsumi, W. et al. (1986): J. Appl. Phys., 60, 2201-2204.

5) Akaogi, M., and Yamazaki, T. (1991): Proc. Japan Acad., 67B, 61-65.

6) Bundy, F. P. (1975): Rev. Sci. Instrum., 46, 1318-1324.

7) Yagi, T. et al. (1992): Phys. Rev., B, 46, 6031-6039.

8) Ringwood, A. E. et al. (1989): Ann. Report 1989 of Reseach School of Earth Sciences, ANU, pp. 38-43.

9) Irifune, T. et al. (1992): High-Pressure Research: Applications to Earth and Planetary Sciences (eds. Y. Syono and M. H. Manghnani). TERRA PUB./AGU, pp. 43-50.

10) Ito, E., and Yamada, H. (1982): High-Pressure Research in Geophysics (eds. S. Akimoto and M. H. Manghnani). CAPJ/REIDEL, pp. 405-419.

11) Ito, E., and Takahashi, E. (1989): J. Geophys. Res., 94, 10637-10646.

12) Irifune, T., and Ringwood, A. E. (1987): Earth Planet. Sci. Lett., 86, 365-376.

13) Irifune, T. et al. (1989): Abst. 30th High Press. Conf. Japan, pp. 186-187 (in Japanese).

14) Yoneda, A. et al. (1984): High Temp.-High Press, 16, 637-656. 